\title{
Picosecond Pulse Radiolysis of Propylene Carbonate as a So- lute in Water and as a Solvent
}

Jean-Louis Marignier, ${ }^{1}$ Fayçal Torche, ${ }^{1}$ Sophie Le Caër, ${ }^{2}$ Mehran Mostafavi ${ }^{1}$ and Jacqueline Belloni ${ }^{1}$

${ }^{1}$ Laboratoire de Chimie-Physique/ELYSE, UMR 8000 CNRS/UPS, Univ. Paris Sud, Université Paris-Saclay, Bât. 349, F91405 Orsay Cedex, France.

${ }^{2}$ LIONS, NIMBE, CEA, CNRS, Université Paris Saclay, CEA Saclay, F-91191 Gif-sur-Yvette Cedex, France.

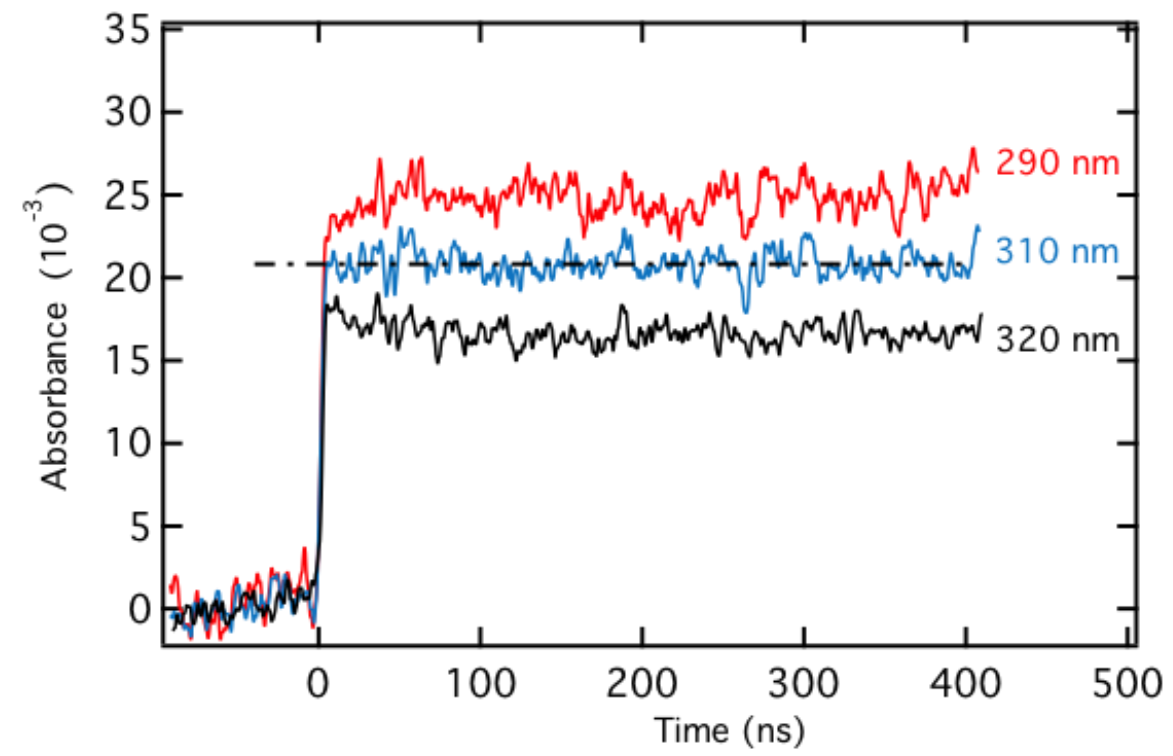

Figure S1. Absorbance kinetics at 290, 310 and $320 \mathrm{~nm}$ in aqueous solutions of PC $2 \mathrm{~mol} \mathrm{~L}^{-1}$ and ter-butanol $0.5 \mathrm{~mol} \mathrm{~L}^{-1}$ (Dw : 36 Gy/pulse).

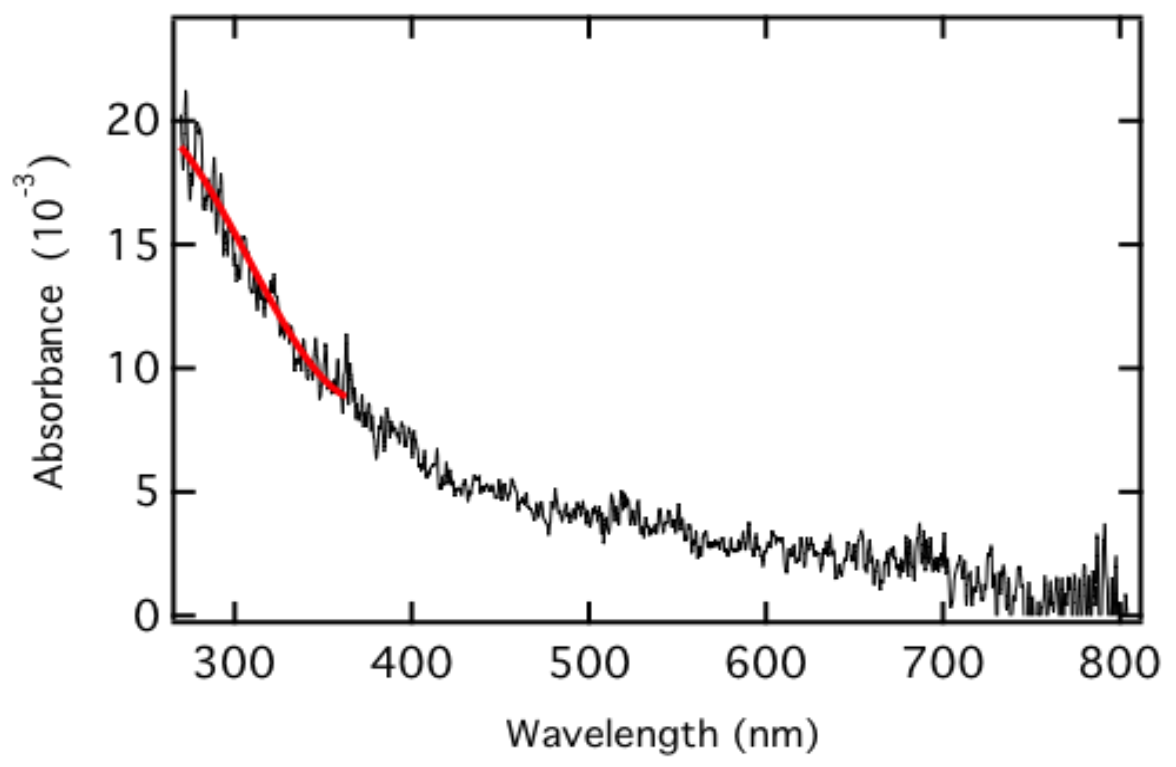

Figure S2. Transient spectrum in neat propylene carbonate at $60 \mathrm{~ns}$ after the pulse. $D_{P C}=48 \mathrm{~J} \mathrm{~L}^{-1}$. For comparison, the red line is the normalized absorption spectrum of $\mathrm{PC}^{-\bullet}$ in $\mathrm{H}_{2} \mathrm{O}$ taken from Figure 3. 


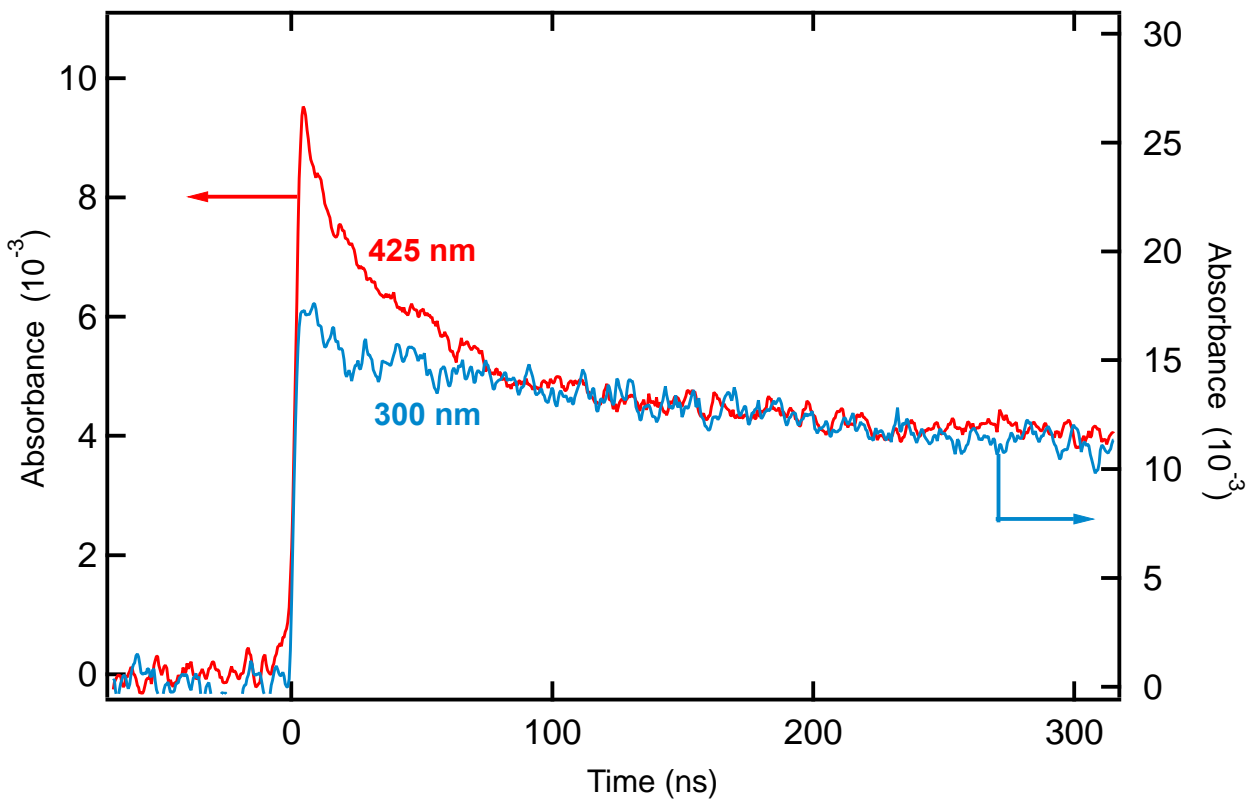

Figure S3. Comparison between the absorbance decays at $300 \mathrm{~nm}$ (right ordinates) and $425 \mathrm{~nm}$ (left ordinates) in neat PC. $D_{P C}$ $=48 \mathrm{~J} \mathrm{~L}^{-1}$.

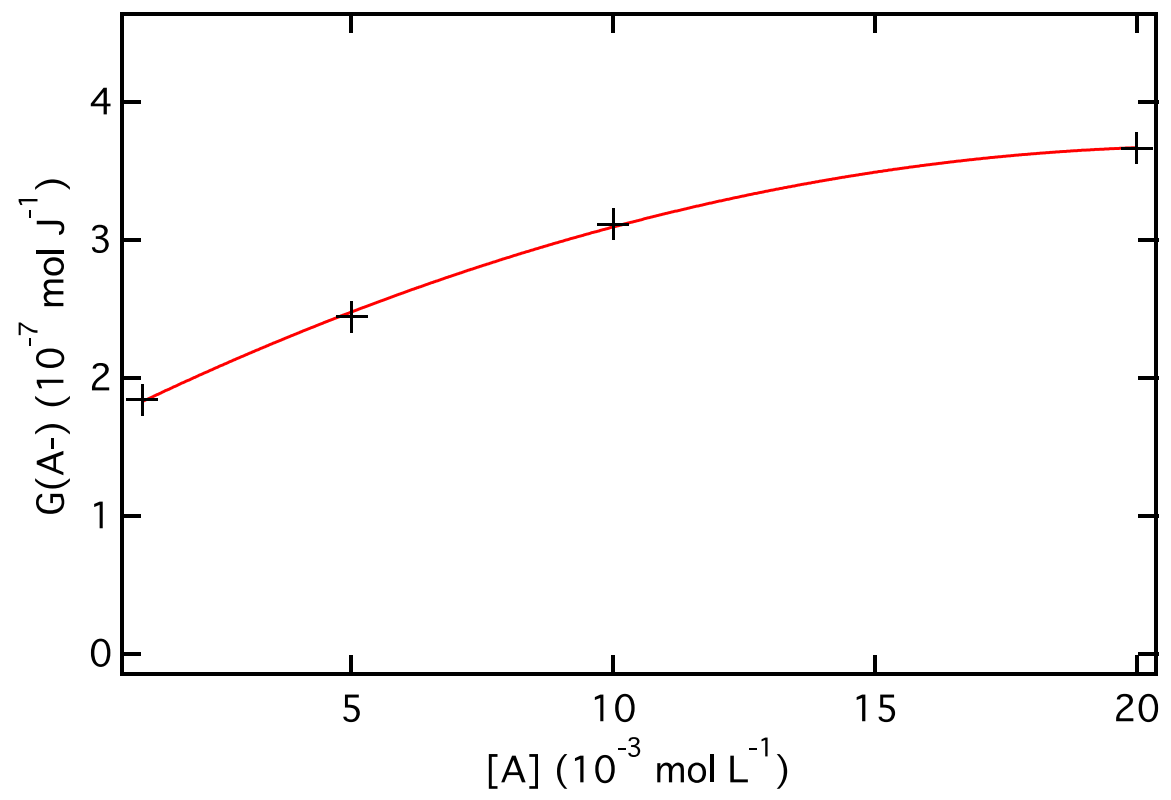

Figure S4. Dependence of the yield of the radical anion $\mathrm{An}^{-\bullet}$ on the anthracene concentration in $\mathrm{PC}$ solvent. $D_{P C}=65 \mathrm{~J} \mathrm{~L}^{-1}$. 


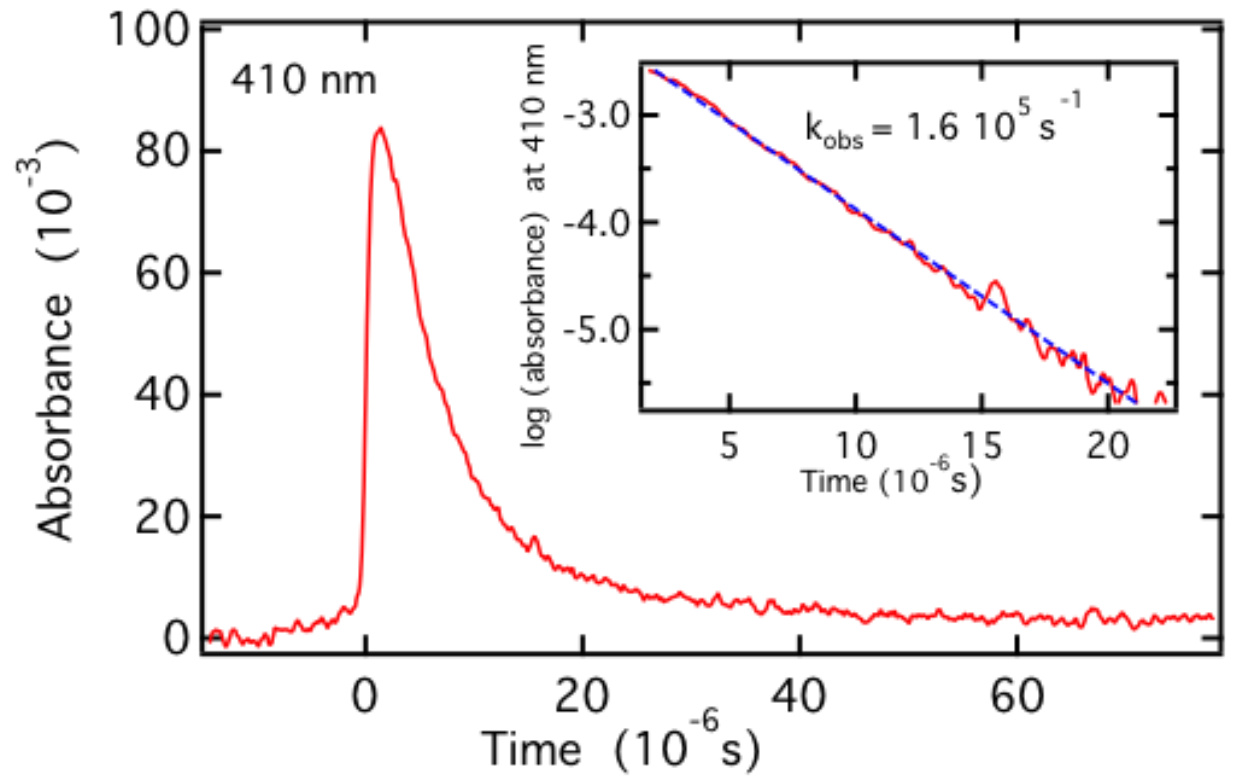

Figure S5. Absorbance decay at $410 \mathrm{~nm}$ in a solution containing $0.1 \mathrm{~mol} \mathrm{~L}^{-1} \mathrm{Ph}_{2}$ in $\mathrm{PC}, D_{P C}=48 \mathrm{~J} \mathrm{~L}^{-1}$. Inset : pseudo-first order plot and rate constant. 